\title{
Expression and clinical significance of periostin in oral lichen planus
}

\author{
ZHI-RUI ZHANG ${ }^{1}$, LI-YA CHEN ${ }^{1}$, HONG-YAN QI ${ }^{1}$ and SHAO-HUA SUN ${ }^{2}$ \\ Departments of ${ }^{1}$ Stomatology and ${ }^{2}$ Pathology, First Hospital of Lanzhou University, Lanzhou, Gansu 730000, P.R. China
}

Received December 17, 2017; Accepted March 14, 2018

DOI: $10.3892 /$ etm.2018.6029

\begin{abstract}
Oral lichen planus (OLP) is a chronic inflammatory lesion involving the oral mucosa, which has a high likelihood of progressing to cancer. The present study investigated the periostin expression in the mucosa and serum of patients with OLP and its correlation with serum cytokines. A total of 117 patients with OLP and 110 healthy controls were included in the study. The protein expression of periostin were measured in the OLP and normal oral mucosa by immunohistochemistry. ELISA was performed to measure the serum levels of periostin, tumour necrosis factor- $\alpha$ (TNF- $\alpha$ ), interleukin (IL)-6, interferon- $\gamma($ IFN- $\gamma)$, IL-4 and thymic stromal lymphopoietin (TSLP). Compared with the control group the OLP group had a significantly increased number of cases with high periostin expression in the oral mucosa and a significantly increased serum periostin level $(\mathrm{P}<0.05)$. Among all 117 OLP subjects, high periostin expression was associated with higher serum IL-6, TNF- $\alpha$, TSLP and tissue mast cell density. High periostin expression was also significantly associated with a lower IFN- $\gamma / \mathrm{IL}-4$ ratio $(\mathrm{P}<0.05)$. The present study concluded that periostin expression was increased in the oral mucosa and serum of patients with OLP and was associated with inflammatory response, T helper 2 cytokine-predominant immune imbalance, increased mast cell count and TSLP. The modulation of periostin may represent an attractive novel therapeutic target.
\end{abstract}

\section{Introduction}

Oral lichen planus (OLP) is an inflammatory disease that affects oral mucosa, with a prevalence of 0.5 to $2.0 \%$ among the general population. This disease is more common in middle-aged patients (30-60 years) and affects more females than males (1). The pathogenesis of OPL remains unclear, and

Correspondence to: Dr Zhi-Rui Zhang, Department of Stomatology, First Hospital of Lanzhou University, 1 West Donggang Road, Lanzhou, Gansu 730000, P.R. China

E-mail: zhangzr56789@163.com

Key words: oral lichen planus, periostin, proinflammatory cytokine, mast cell, thymic stromal lymphopoietin it is generally considered to be an immunologically mediated process, including cytotoxic $\mathrm{T}$ cells activation and mast cell degranulation, thus demonstrating a hypersensitivity reaction (2). In oral mucosa of OLP, $\mathrm{CD}^{+} \mathrm{T}$ cells infiltrate in epithelium-connective tissue interface and promote apoptosis of oral epithelial cells at the basal layer (3). A large clinical investigation among 7,806 patients showed that OLP has a malignant transformation rate of about $1.09 \%$ that develop oral squamous cell carcinoma (OSCC) (4). The mechanisms underlying carcinogenesis of OLP include epithelial cell proliferation and apoptosis, deregulation of oncogenes and tumor-suppressor genes, oxidative stress and inflammatory process (5). Currently histology is the main method to evaluate the clinical severity and potential risk of malignant transformation of OLP. New biomarkers are highly needed to indicate the transformation potential of OLP, thus will greatly improving the accurate evaluation of OLP.

Periostin is a soluble and secreted extracellular matrix protein and plays various roles in embryonic development, injury, tooth and bone formation (6). Periostin expression is upregulated in various tumor types, such as breast, lung, ovarian, prostate, gastric, colon and pancreatic cancers (7). Furthermore, periostin participates in various biologic processes of tumorigenesis, including cell survival, proliferation, adhesion, angiogenesis, epithelial-mesenchymal transition (EMT), tumor invasion and metastasis (8). However, there were no studies about the role of periostin in OLP, as well as the associations between periostin and clinicopathological parameters of OLP.

In this study, periostin protein level in OLP was measured by immunohistochemistry (IHC) and enzyme-linked immunosorbent assay (ELISA), and the correlations between periostin and clinicopathological process of OLP were analyzed. Our study may provide periostin as a new biomarker for the early diagnosis and treatment of OLP.

\section{Materials and methods}

Subjects. A total of 117 consecutive OLP patients were included in the First Hospital of Lanzhou University (Lanzhou, China) between July 2012 and December 2015, and their tissue specimens and serums were obtained. Before sampling, the patients had not received any treatment. The OLP was diagnosed based on clinical appearance and paraffin-embedded tissue specimens stained with hematoxylin and eosin (H\&E) 
by a pathologist. Any OLP patients with history of systemic disease or inflammatory disease, oral candida infection, oral lichenoid reactions, pregnancy or using antibiotic within one month before diagnosis were excluded. The samples of oral mucosa and serum were obtained from a study group of 45 males and 72 females, with ages ranging from 28 to 72 years (median age, 52 years). The clinicopathological data including age, gender and clinical type were obtained. There were 110 normal oral mucosal tissue and their serums serving as the control group, which were harvested from patients with alveolar bone cyst who underwent paraneoplastic plastic surgery and had no any systemic disease. This study was approved by the ethics committee of the First Hospital of Lanzhou University. Informed consent was signed by the patients or their relatives.

$I H C$. The periostin protein levels in tissue specimens of OLP and controls were determined by IHC staining using avidin-biotin-peroxidase complex (ABC) method. All formalin-fixed and paraffin-embedded oral tissue specimens were processed for $5 \mu \mathrm{m}$-thick sections. The sections were dewaxed in xylene and rehydrated with descending alcohol gradient, and then were incubated with $0.3 \%$ hydrogen peroxidase for $25 \mathrm{~min}$ to block the endogenous peroxidase activity. The sections were heated with $700 \mathrm{~W}$ microwave oven for $15 \mathrm{~min}$ for antigen retrieval, and then incubated with rabbit anti-periostin primary antibody (1:150; ab92460; Abcam, Shanghai, China) at room temperature for $2 \mathrm{~h}$, followed by incubation with biotinylated secondary antibody (mouse anti-rabbit IgG; 1:500 dilution; Zhongshan Jinqiao Biology \& Technology Co., Ltd., Beijing, China). The 3,3'-diaminobenzidine tetra-hydrochloride (liquid DAB+; Dako, Glostrup, Denmark) and hematoxylin were used to visualize the antigen-antibody reactions. Finally, the sections were dehydrated and mounted. The sections of negative controls were incubated with phosphate-buffered saline other than primary antibody.

Evaluation of immunohistochemical staining. Two experienced pathologists who were blinded to the clinical data independently evaluated the stained slices. Five visual fields were randomly selected for evaluation in each section. The expression of periostin for each case was evaluated based on the percentage of positive cell and staining intensity. Grading of stain-positive cells was as follows: 0, stain-positive cells $<5 \%$; 1, stain-positive cells 5-25\%; 2, stain-positive cells $26-50 \% ; 3$, stain-positive cells $>50 \%$. Grading of staining intensity was as follows: 0 , negative; 1 , light yellow; 2 , brownish-yellow; 3, brown. The total score=Grading of stain-positive cells x Grading of staining intensity. For statistical analyses, the cases that were found to have total score of $\geq 4$ and $<4$ were considered high expression and low expression of periostin, respectively (9).

Measurement of serum periostin, interleukin (IL)-6, tumour necrosis factor- $\alpha$ (TNF- $\alpha)$, interferon- $\gamma(I F N-\gamma), I L-4$ and thymic stromal lymphopoietin (TSLP) concentration. Venous blood samples were collected from OLP subjects and controls, and centrifugation was performed within $30 \mathrm{~min}$ at $1,000 \mathrm{x} \mathrm{g}$ for $15 \mathrm{~min}$. The serum was separated and stored in aliquots at $-70^{\circ} \mathrm{C}$ until measurement. ELISA kits (R\&D Systems, Inc., Minneapolis, MN, USA) were applied to measure the serum concentrations of periostin (DY3548), IL-6 (DY206), TNF- $\alpha$ (DY210), IFN- $\gamma$ (DY285), IL-4 (DY204-05) and TSLP (DY1398). The absorbance at OD450 wavelength was measured by an ELISA plate reader (Ricso RK201; Shenzhen Ricso Technology Co., Ltd., Shenzhen, China). All samples were measured in triplicate to calculate the mean concentration of each subject.

Counting of mast cells. Toluidine blue (1\%) is used to evaluate mast cell density by selectively staining mast cells of oral mucosa tissue. In mast cells, the granules were stained with purplish red and the nuclei with sky blue in colour. The number of mast cells was counted under a an microscope (BX51; Olympus Corporation, Tokyo, Japan; magnification, $\mathrm{x} 400)$. Mast cell density was expressed as the mast cell number per square millimeter $\left(\mathrm{MCs} / \mathrm{mm}^{2}\right)(10)$.

Statistical analysis. Data were statistically analyzed using SPSS 19.0 (SPSS, Inc., Chicago, IL, USA) software. Continuous variables were expressed as medians and interquartile ranges. Categorical variables were expressed as frequencies and percentages. Differences between two or three groups were determined by Wilcoxon-Mann-Whitney test in comparing continuous variables, or by Chi-squared test or a Fisher's exact test in comparing categorical variables. Spearman's rank correlation tests were used to analyze correlations between serum periostin and other variables. $\mathrm{P}<0.05$ was considered to indicate a statistically significant difference.

\section{Results}

Expression of periostin in normal and OLP oral mucosa. The study group of 117 OLP patients included 45 males and 72 females, with ages ranging from 28 to 72 years (median age, 52 years). There were $52(44.4 \%)$ cases of reticular form, $41(35.0 \%)$ cases of erosive form, and $24(20.5 \%)$ cases of atrophic form. The clinical type of OLP was significantly associated with serum cytokine levels, and atrophic form had the highest levels of serum IL-6, TNF- $\alpha$, IL-4, TSLP, oral tissue mast cell density, and the lowest level of serum IFN- $\gamma / \mathrm{IL}-4$ ratio $(\mathrm{P}<0.05$; Table $\mathrm{I})$.

There were 110 healthy controls including 37 males and 73 females, with the ages ranging from 27 to 67 years (median age, 52 years). No significant differences were found in age and gender between control group and OLP group. The protein expression of periostin was determined by IHC in oral epithelium tissues and by ELISA in serums of OLP patients and controls. The periostin protein level was evaluated based on the combination of positive cell percentage and staining intensity, and there were 56 (47.9\%) OLP cases showing high periostin expression, which was significantly higher than that of controls (12 cases, 10.9\%) $(\mathrm{P}<0.001)$. Furthermore, the serum periostin level was significantly higher in OLP group (Median $86.9 \mu \mathrm{g} / \mathrm{l})$ than control group (Median $37.4 \mu \mathrm{g} / \mathrm{l}$ ) $(\mathrm{P}<0.001)$ (Table II). In most cases of OLP, strong periostin staining was found in the oral epithelium, and little or no periostin staining was found in oral epithelium of most controls (Fig. 1A and B), Therefore, in the later study, we divided OLP 
Table I. Characteristics of the study population.

\begin{tabular}{|c|c|c|c|c|c|}
\hline Characteristic & OLP $(n=117)$ & Reticular $(\mathrm{n}=52)$ & Erosive $(n=41)$ & Atrophic $(n=24)$ & P-value \\
\hline Age, years (range) ${ }^{\mathrm{a}}$ & $52(48-55)$ & $52(47-56)$ & $52(48.5-54.5)$ & $51(48-55)$ & 0.918 \\
\hline Male $(\%)^{\mathrm{b}}$ & $45(38.5)$ & $21(40.4)$ & $18(43.9)$ & $6(25.0)$ & 0.296 \\
\hline IL-6, ng/l (range) $)^{\mathrm{a}}$ & $47.4(42.7-53.3)$ & $44.0(38.4-50.4)$ & $48.3(43.2-52.8)$ & $59.2(47.2-66.1)$ & $<0.001$ \\
\hline $\mathrm{TNF}-\alpha, \mathrm{ng} / \mathrm{l}(\text { range })^{\mathrm{a}}$ & $54.4(47.6-61.7)$ & $52.6(45.5-57.1)$ & $54.9(50.1-60.6)$ & $62.7(53.6-69.9)$ & $<0.001$ \\
\hline IFN- $\gamma$, ng/l (range) $)^{a}$ & $27.2(24.8-30.5)$ & $27.2(24.7-30.0)$ & $27.6(26.0-31.0)$ & $25.5(23.9-29.5)$ & 0.241 \\
\hline IL-4, ng/l (range) $)^{\mathrm{a}}$ & $26.5(24.1-28.8)$ & $25.0(21.9-27.6)$ & $26.7(24.5-28.7)$ & $28.3(26.2-31.2)$ & 0.001 \\
\hline IFN- $\gamma /$ IL-4 (range) $)^{a}$ & $1.005(1.065-1.144)$ & $1.085(1.032-1.201)$ & $1.076(1.016-1.143)$ & $0.964(0.813-1.024)$ & $<0.001$ \\
\hline Mast cell, $\mathrm{MCs} / \mathrm{mm}^{2}(\text { range })^{\mathrm{a}}$ & $26(24-29)$ & $25(23-26)$ & $28(26-29)$ & $30(27-32)$ & $<0.001$ \\
\hline TSLP, ng/l (range) $)^{\mathrm{a}}$ & $204.9(185.3-230.9)$ & $196.1(179.8-217.0)$ & $211.3(189.9-229.9)$ & $232.5(191.6-246.7)$ & 0.001 \\
\hline Periostin expression $^{\mathrm{b}}(\%)$ & & & & & 0.012 \\
\hline High & $56(47.9)$ & $18(34.6)$ & $21(51.2)$ & $17(70.8)$ & \\
\hline Low & $61(52.1)$ & $34(65.4)$ & $20(48.8)$ & $7(29.2)$ & \\
\hline
\end{tabular}

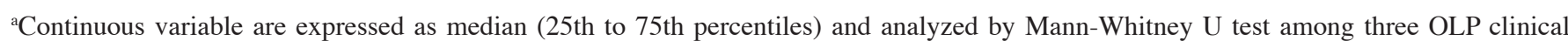
types; ${ }^{b}$ Categorical Variable are expressed as frequency $(\%)$ and analyzed by Chi-squared test among three OLP clinical types. OLP, oral lichen planus; IL, interleukin; TNF- $\alpha$, tumour necrosis factor- $\alpha$; IFN- $\gamma$, interferon- $\gamma$; TSLP, thymic stromal lymphopoietin.

Table II. Comparison between healthy controls and oral lichen planus in tissue and serum periostin expressions.

\begin{tabular}{|c|c|c|c|}
\hline Characteristic & Healthy controls $(n=110)$ & Oral lichen planus $(n=117)$ & P-value \\
\hline Age, years (range) ${ }^{\mathrm{a}}$ & $52(49-55)$ & $52(48-55)$ & 0.624 \\
\hline Male $(\%)^{\mathrm{b}}$ & $37(33.6)$ & $45(38.5)$ & 0.491 \\
\hline Tissue periostin $(\%)^{\mathrm{b}}$ & $12(10.9)$ & $56(47.9)$ & $<0.001$ \\
\hline Serum periostin, $\mathrm{ng} / \mathrm{l}$ (range) ${ }^{\mathrm{a}}$ & $37.4(32.9-48.4)$ & $86.9(70.7-115.2)$ & $<0.001$ \\
\hline
\end{tabular}

${ }^{\mathrm{a} C}$ Continuous variable are expressed as median (25th to 75 th percentiles) and analyzed by Mann-Whitney U test; ${ }^{\mathrm{b} C a t e g o r i c a l ~ V a r i a b l e ~ a r e ~}$ expressed as frequency $(\%)$ and analyzed by Chi-squared test.

subjects into high periostin group $(n=56)$ and low periostin group $(\mathrm{n}=61)$ according the results of IHC.

The periostin expression was significantly associated with OLP clinical type. Atrophic form had the highest percentage (17/24) of high tissue periostin expression among all three OLP clinical types $(\mathrm{P}<0.05$; Table I). Moreover, serum periostin levels in erosive form and atrophic form were significantly higher compare with that in reticular form $(\mathrm{P}<0.001$; Fig. 1C). There was significant correlation between tissue periostin expression and serum periostin level, which was supported by significantly higher serum periostin level in high periostin group compared with low periostin group (Fig. 1D).

Association between periostin expression and proinflammatory cytokine levels. To further investigate the clinical significance of periostin in OLP, the correlations between periostin expression and proinflammatory cytokine levels in 117 patients were analyzed. Serum IL- 6 and TNF- $\alpha$ levels were significantly higher in high periostin group compared with low expression group (Fig. 2A and B). Furthermore, serum periostin level was correlated positively to IL-6 ( $\mathrm{r}=0.321$, $\mathrm{P}<0.001)$ and TNF- $\alpha(\mathrm{r}=0.360, \mathrm{P}<0.001$; Fig. $2 \mathrm{C}$ and $\mathrm{D})$.

Association between the periostin expression and IFN- $\gamma / I L-4$ ratio. The serum IFN- $\gamma$ concentrations showed no statistically significant between periostin-high group and periostin-low group $(\mathrm{P}=0.750$; Fig. $3 \mathrm{~A})$. The serum IL-4 concentrations were significant higher in patients with periostin-high than in patients with periostin-low ( $\mathrm{P}=0.005$; Fig. 3B). The serum IFN- $\gamma /$ IL-4 ratio was significantly lower in OLP patients with periostin-high than in those with periostin-low $(\mathrm{P}=0.003$; Fig. 3C). Furthermore, we found negetive correlation between the serum periostin level and serum IFN- $\gamma / \mathrm{IL}-4$ ratio $(r=0.369$, $\mathrm{P}<0.001$; Fig. 3D).

Association between the periostin expression and mast cell count. Total number of mast cells stained with TB showed significantly higher in oral tissue of patients with periostin-high $\left(\right.$ median $\left.=28 \mathrm{MCs} / \mathrm{mm}^{2}\right)$ than that with periostin-low $\left(\right.$ median=26 MCs $\left./ \mathrm{mm}^{2}\right)$ (Fig. 4A). Positive correlation was observed between the serum periostin level and mast cell 

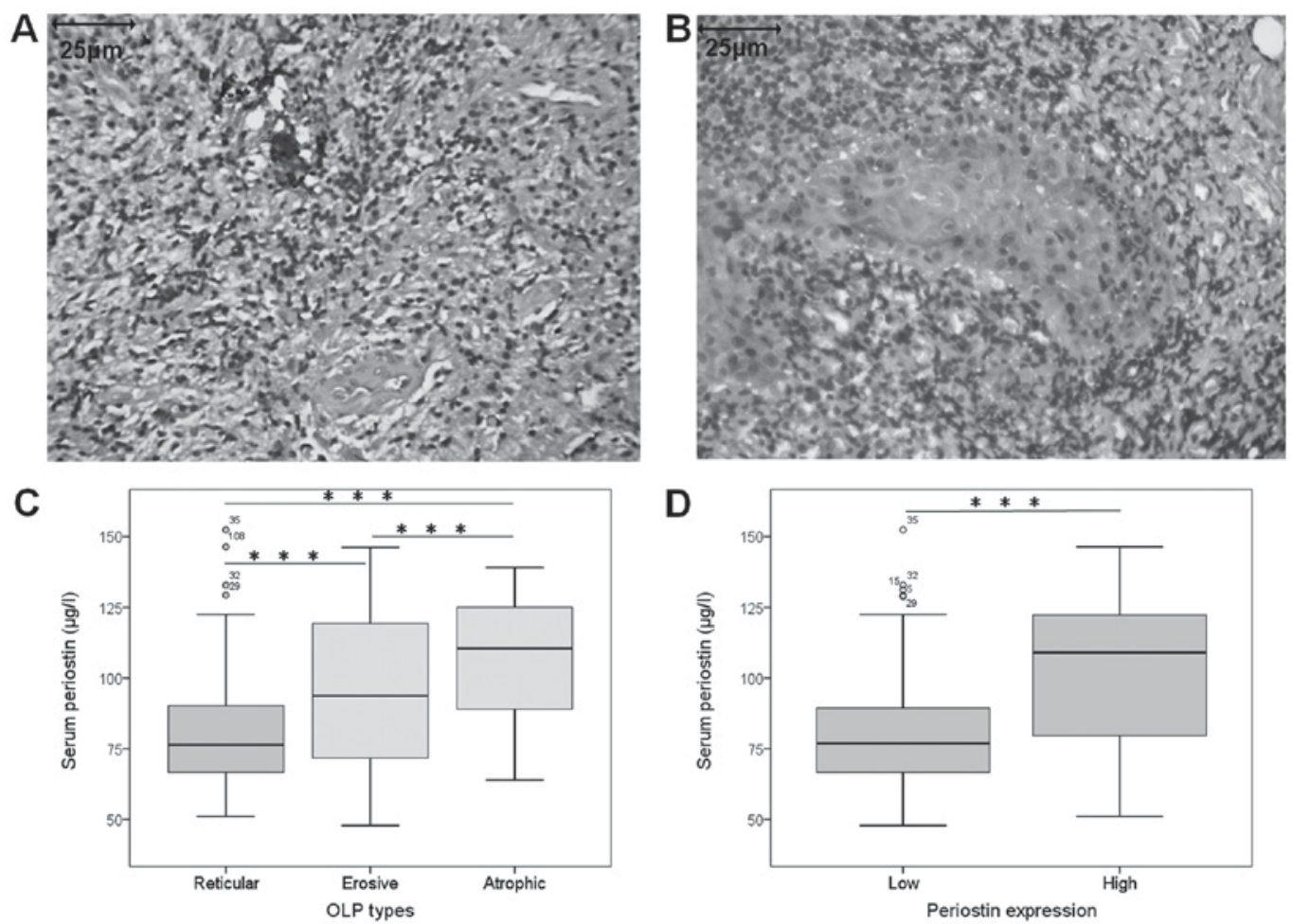

Figure 1. Expression of periostin in patients with OLP participants with normal oral mucosa. Immunohistochemical staining of periostin was shown in normal and OLP tisssues. (A) Periostin protein expression was low in normal oral mucosa tissues. (B) Periostin protein expression was high in OLP oral mucosa tissues (magnification, x400). Serum periostin concentrations were measured by ELISA in OLP patients. (C) Serum periostin levels are significantly higher in erosive form $(n=41)$ and atrophic form $(n=24)$ as compared with reticular form $(n=52)(P<0.001)$. (D) Serum periostin levels are significantly higher in the periostin high group ( $\mathrm{n}=56)$ compared with the periostin low group $(\mathrm{n}=61)$ of OLP patients. Box plots are displayed to show median per group (bold black line) and minimum and maximum values (horizontal lines). Wilcoxon-Mann-Whitney test was performed. ${ }^{* * *} \mathrm{P}<0.001$. OLP, oral lichen planus.
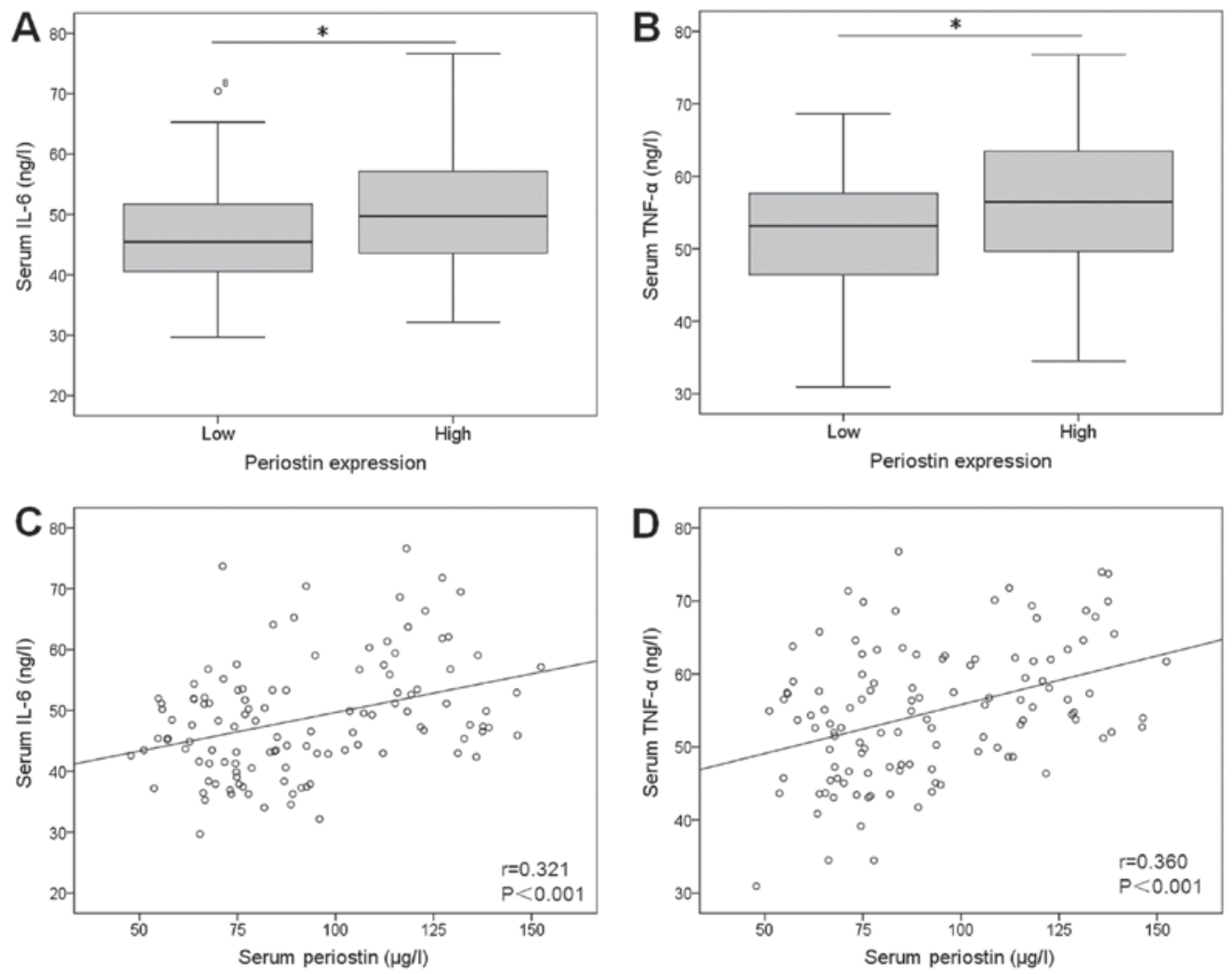

Figure 2. Association between serum proinflammatory cytokine levels and periostin expression in OLP. Serum (A) IL-6 and (B) TNF- $\alpha$ levels were significantly higher in the periostin high group $(\mathrm{n}=56)$ as compared with the periostin low group $(\mathrm{n}=61)$ of OLP patients $(\mathrm{P}<0.05)$. Serum periostin was signifiacntly correlated with (C) IL-6 ( $r=0.321, \mathrm{P}<0.001)$ and (D) TNF- $\alpha(\mathrm{r}=0.360, \mathrm{P}<0.001)$. Spearman's rank correlation test was performed. "P<0.05. OLP, oral lichen planus; IL, interleukin; TNF- $\alpha$, tumour necrosis factor- $\alpha$. 

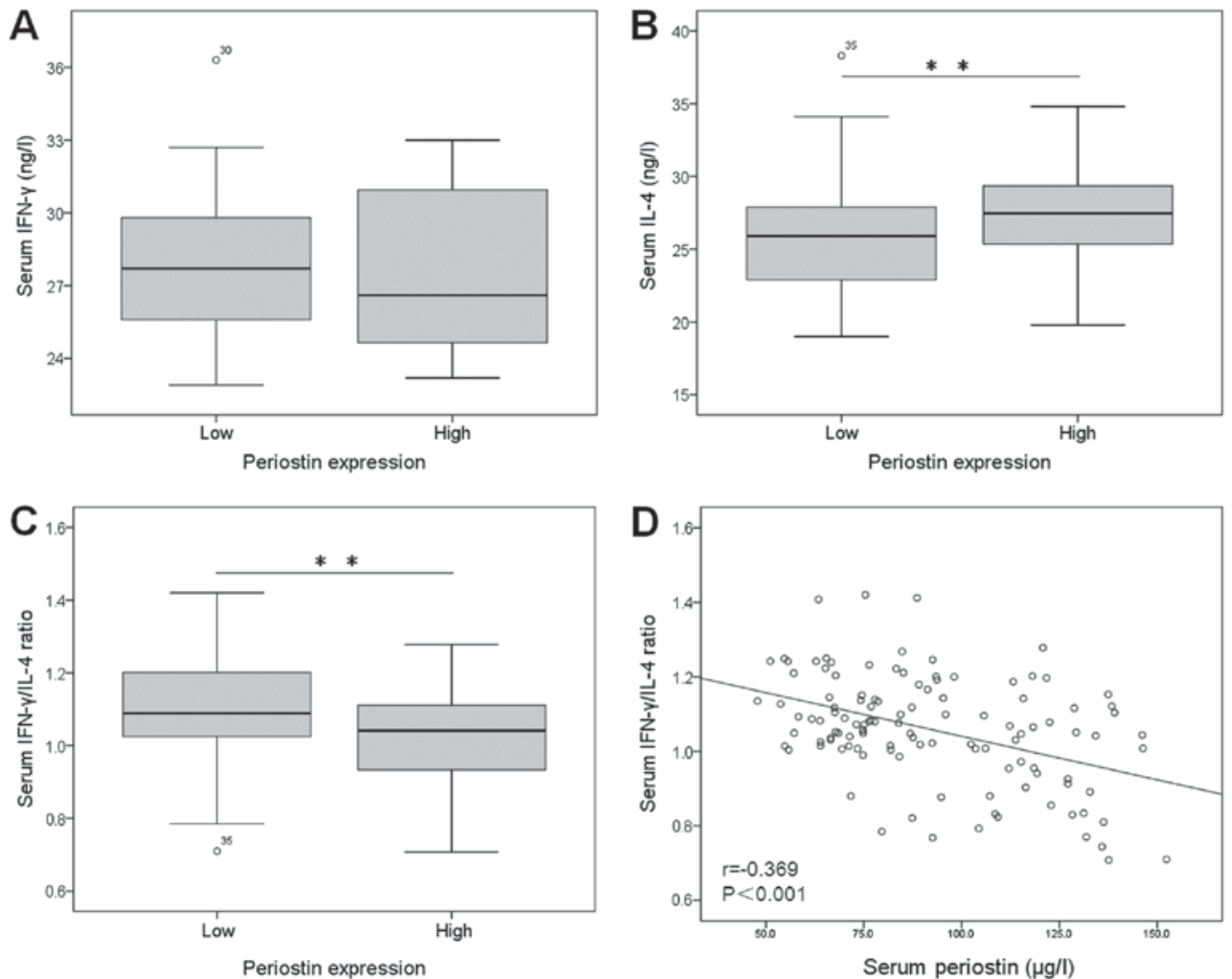

Figure 3. Association between serum IFN- $\gamma /$ IL-4 ratio and periostin expression in OLP. Serum (A) IFN- $\gamma$, (B) IL-4 and (C) IFN- $\gamma /$ IL-4 ratio levels were significantly higher in the periostin high group $(\mathrm{n}=56)$ compared with the periostin low group $(\mathrm{n}=61)$ of OLP patients. Serum periostin was strongly correlated with (D) IFN- $\gamma /$ IL-4 ( $r=-0.369, \mathrm{P}<0.001)$. Spearman's rank correlation test was performed. ${ }^{* *} \mathrm{P}<0.01$. OLP, oral lichen planus; IL, interleukin; IFN- $\gamma$, interferon- $\gamma$.
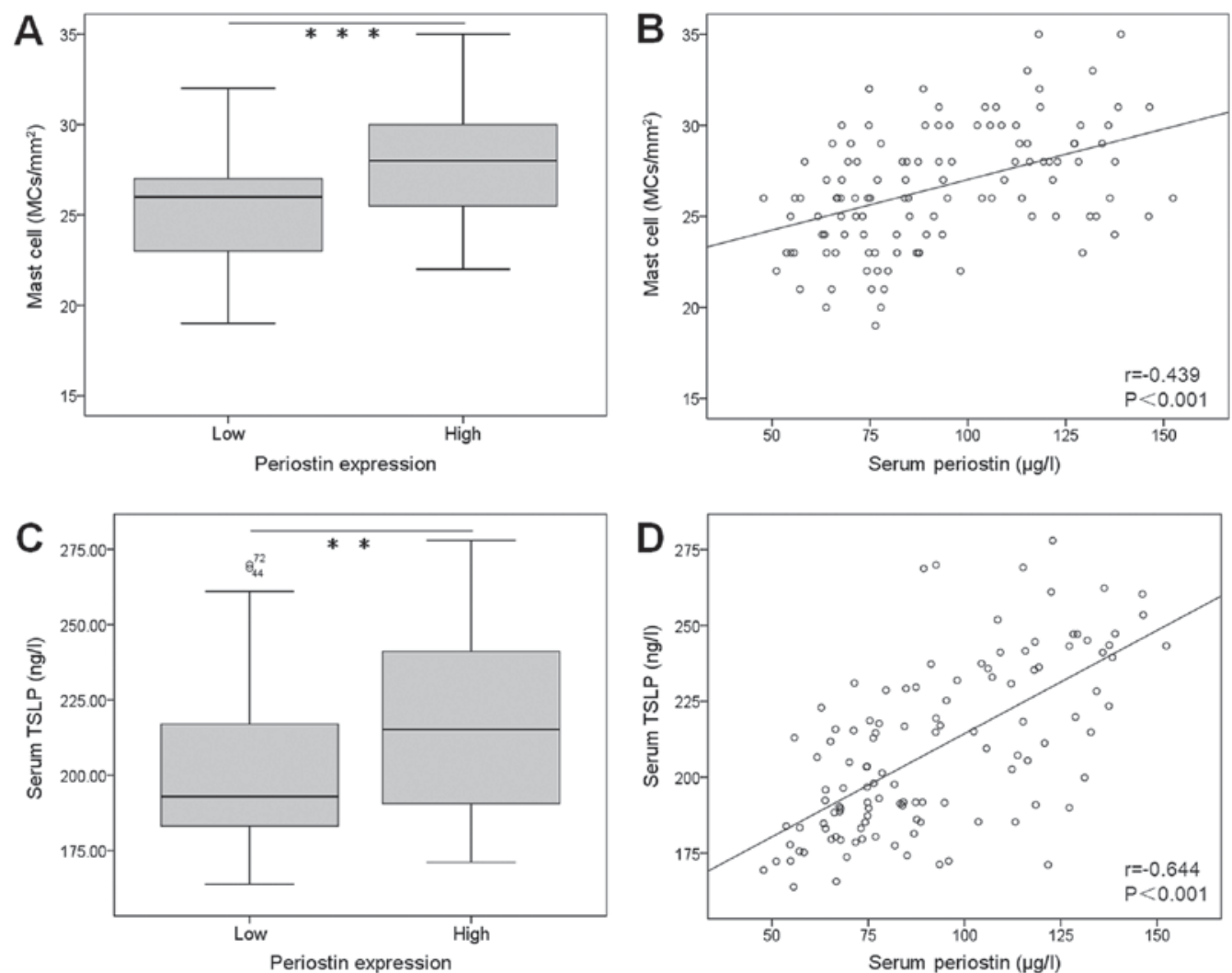

Figure 4. Association of mast cell number and serum TSLP with periostin expression in OLP. (A) The mast cell number in oral mucosa of OLP was significantly higher in periostin high group $(n=56)$ as compared with periostin low group $(n=61 ; P<0.001)$. (B) Serum periostin was strongly correlated with mast cell number $(\mathrm{r}=0.439, \mathrm{P}<0.001)$. (C) Serum TSLP of OLP was significantly higher in the periostin high group ( $\mathrm{n}=56)$ compared with the periostin low group $(\mathrm{n}=61 ; \mathrm{P}=0.008)$. (D) Serum periostin was strongly correlated with serum TSLP $(\mathrm{r}=0.644, \mathrm{P}<0.001)$. Spearman's rank correlation test was performed. ${ }^{* *} \mathrm{P}<0.01$, ${ }^{* * *} \mathrm{P}<0.001$. OLP, oral lichen planus; TSLP, thymic stromal lymphopoietin. 
density in oral tissue of OLP subjects $(\mathrm{r}=0.439, \mathrm{P}<0.001$; Fig. 4B).

Association between the periostin expression and serum TSLP. The serum concentration of TSLP was significantly higher in patients with periostin-high than those with periostin-low ( $\mathrm{P}<0.01$; Fig. 4C). There was positive correlation between the serum periostin level and TSLP in OLP subjects $(\mathrm{r}=0.644$, $\mathrm{P}<0.001$; Fig. 4D).

\section{Discussion}

In this study, we measured periostin expression in 117 OLP subjects and found that periostin protein levels were significantly higher in oral mucosa and serum compared with those in controls. The high periostin expression was positively correlated with serum IL-6, TNF- $\alpha$, TSLP and tissue mast cell density, and negatively correlated with IFN- $\gamma /$ IL-4 ratio. Our study provides a new biomarker for clinical status and malignant potential of OLP.

Our study showed that high expression of periostin was detected in more cases of OLP specimens than those of normal oral mucosa specimens. Other report showed that periostin expression was higher in OSCC tumor tissue compared with control tissue (11), and periostin protein level was significantly correlated with OSCC invasion and metastasis (12). This indicates that periostin has cancerous potential and might play roles in malignant transformation of OLP. In fact, our results showed that periostin expression was significantly higher in OLP with erosive and atrophic forms, two OLP clinical types with the highest malignant transformation rate (13). Furthermore, serum periostin levels were also significantly higher in OLP subjects than in controls, and positive correlation was observed between tissue periostin and serum periostin levels. These indicate that the serum periostin might come from oral mucosa, as periostin is a soluble and secreted extracellular matrix protein. Therefore, serum periostin may act as a biomarker for evaluating clinical status and malignant transformation potential of OLP patients.

Our results showed the association between periostin expression and inflammatory response, as evidenced by increased serum IL-6 and TNF- $\alpha$ level in periostin high group compared with periostin low group, and our results are in accordance with other report (14). Chronic inflammation is an important mechanism of OLP and it participates in the development and progression to OSCC (15). Aberrant production of cytokines may lead to immune deficiency or autoimmunity, which are involved in the mechanisms of OLP (16). Periostin is also a protein involved in inflammatory response and could produce tumor-promotive microenvironments (17). Treatment with TNF- $\alpha$ could significantly increase in periostin expression in intestinal epithelial cells (18), and this indicates that inflammation can promote the production of periostin. Furthermore, periostin is also a promotor of inflammation and can activating NF- $\mathrm{kB}$ signaling, thereby increasing IL-6 production (19). Therefore, a positive feedback loop may exist in OLP that induce the interaction between periostin and proinflammatory cytokines.

Our results showed the serum IFN- $\gamma / \mathrm{IL}-4$ ratio was significantly lower in periostin-high group compared with periostin-low group, and a negative correlation was observed between serum periostin and IFN- $\gamma /$ IL-4 ratio. In mucosal immune response, CD4+ T lymphocytes can differentiate into two functionally distinct populations with opposite effects, T helper 1 (Th1) cells and Th 2 cells. IFN- $\gamma$ and IL- 4 are two principal cytokines which are produced from Th1 and Th2 cells respectively, thus maintaining Th1/Th2 balance (20). OLP patient showed a lower IFN- $\gamma /$ IL- 4 ratio in both serum and saliva, especially in erythematous/ulcerative group compared with the reticular group (21). This indicates OLP is a Th2 cytokine-predominant disorder and Th2 immune imbalance may lead to immunosuppression and increase the risk for malignant transformation. In allergic skin inflammation mouse model, Th2 cytokines IL-4 and IL-13 could stimulate periostin production, thereby inducing proinflammatory cytokines and accelerating Th2-type immune responses (22). Therefore, in our study, periostin may mediate the inflammatory response induced by $\mathrm{Th} 2 \mathrm{immune}$ imbalance.

We found OLP patients with high periostin expression showed increased total number of mast cells in oral mucosa tissue than patients with low periostin, and the mast cell density was positively correlated to serum periostin levels. Mast cell count was higher in oral mucosa of OLP compared to that of healthy controls (23). Currently, the association between mast cell and periostin remains unclear. A report showed that mast cell count was higher in oral submucous fibrosis (OSMF) than in normal buccal mucosa (24). OSMF is a premalignant mucosal disease with inflammation and progressive fibrosis. As an inducer of fibrosis in various tissues, periostin might mediate the fibrosis process of OSMF (25), and the potential regulatory roles of periostin in mast cells of OLP deserve further investigation (26).

Our results showed the serum TSLP was significantly higher in periostin-high group compared with periostin-low group, and a positive correlation was found between the serum TSLP and periostin levels. TSLP is a cytokine that can activate dendritic cells to induce Th2-mediated inflammation (27). In OLP subjects, the TSLP-positive cells in oral epithelium and the TSLP serum level were significantly increased than in normal controls (28). The pathogenesis of TSLP in OLP may be associated with activating Th2 cytokine production and enhanced mast cell proliferation (29). Periostin can contribute chronic inflammation by stimulating TSLP production in lesional skin of cutaneous T-cell lymphoma (30). Therefore, in our study the high serum TSLP may induced by overexpressed periostin in oral epithelium of OLP, and the detailed mechanism underlying TSLP production by periostin in OLP deserve further investigation.

In conclusion, the expression of periostin is significantly elevated in oral epithelium and serum of OLP patients, which indicates higher malignant potential of OLP. The high periostin expression in OLP is positively correlated with serum IL-6, TNF- $\alpha$, TSLP and tissue mast cell density. Periostin may cause chronic inflammation, stimulating TSLP production and mast cell proliferation, and direct the autoimmune response towards Th2 immune imbalance. Periostin might promote malignant transformation of OLP, which required verification in future studies with larger sample size. More investigation is needed to elucidate the mechanisms of periostin in OLP canceration processes by in vitro and in vivo experimental studies. 


\section{Acknowledgements}

Not applicable.

\section{Funding}

This study was supported in part by grants from the Gansu Natural Science Foundation (2008GS01177).

\section{Availability of data and materials}

The datasets used and/or analyzed during the current study are available from the corresponding author on reasonable request.

\section{Author's contributions}

ZRZ designed the study and wrote the manuscript. LYC and HYQ performed all the experiments and collected the data. SHS analyzed the data.

\section{Ethics approval and consent to participate}

This study was approved by the Ethics Committee of the First Hospital of Lanzhou University. Informed consent was signed by the patients or their relatives.

\section{Consent for publication}

Written informed consent was obtained from the patients or their relatives for the publication of their data.

\section{Competing interests}

The authors declare that they have no competing interests.

\section{References}

1. Alrashdan MS, Cirillo N and McCullough M: Oral lichen planus: A literature review and update. Arch Dermatol Res 308: 539-551, 2016.

2. Krupaa RJ, Sankari SL, Masthan KM and Rajesh E: Oral lichen planus: An overview. J Pharm Bioallied Sci 7 (Suppl 1): S158-S161, 2015.

3. Eversole LR: Immunopathogenesis of oral lichen planus and recurrent aphthous stomatitis. Semin Cutan Med Surg 16: 284-294, 1997

4. Fitzpatrick SG, Hirsch SA and Gordon SC: The malignant transformation of oral lichen planus and oral lichenoid lesions: A systematic review. J Am Dent Assoc 145: 45-56, 2014.

5. Kurago ZB: Etiology and pathogenesis of oral lichen planus: An overview. Oral Surg Oral Med Oral Pathol Oral Radiol 122: 72-80, 2016.

6. Rios H, Koushik SV, Wang H, Wang J, Zhou HM, Lindsley A, Rogers R, Chen Z, Maeda M, Kruzynska-Frejtag A, et al: Periostin null mice exhibit dwarfism, incisor enamel defects, and an early-onset periodontal disease-like phenotype. Mol Cell Biol 25: 11131-11144, 2005.

7. Ratajczak-Wielgomas K and Dziegiel P: The role of periostin in neoplastic processes. Folia Histochem Cytobiol 53: 120-132, 2015.

8. Ruan K, Bao S and Ouyang G: The multifaceted role of periostin in tumorigenesis. Cell Mol Life Sci 66: 2219-2230, 2009.

9. Jia W, Wang W, Ji CS, Niu JY, Lv YJ, Zhou HC and Hu B Coexpression of periostin and EGFR in patients with esophageal squamous cell carcinoma and their prognostic significance. Onco Targets Ther 9: 5133-5142, 2016.
10. Madhuri AR, Alka KD and Ramakanth N: Mast cells are increased in leukoplakia, oral submucous fibrosis, oral lichen planus and oral squamous cell carcinoma. JOMFP 11: 18-22, 2007.

11. Choi P, Jordan CD, Mendez E, Houck J, Yueh B, Farwell DG, Futran $\mathrm{N}$ and Chen $\mathrm{C}$ : Examination of oral cancer biomarkers by tissue microarray analysis. Arch Otolaryngol Head Neck Surg 134: 539-546, 2008.

12. Siriwardena BS, Kudo Y, Ogawa I, Kitagawa M, Kitajima S, Hatano H, Tilakaratne WM, Miyauchi M and Takata T: Periostin is frequently overexpressed and enhances invasion and angiogenesis in oral cancer. Br J Cancer 95: 1396-1403, 2006.

13. Agha-Hosseini F, Sheykhbahaei N and SadrZadeh-Afshar MS Evaluation of potential risk factors that contribute to malignant transformation of oral lichen planus: A literature review. J Contemp Dent Pract 17: 692-701, 2016.

14. Kaur J and Jacobs R: Proinflammatory cytokine levels in oral lichen planus, oral leukoplakia, andoral submucous fibrosis. J Korean Assoc Oral Maxillofac Surg 41: 171-175, 2015.

15. Liu Y, Messadi DV, Wu H and Hu S: Oral lichen planus is a unique disease model for studying chronic inflammation and oral cancer. Med Hypotheses 75: 492-494, 2010.

16. Lu R, Zhang J, Sun W, Du G and Zhou G: Inflammation-related cytokines in oral lichen planus: An overview. J Oral Pathol Med 44: 1-14, 2015.

17. Liu AY, Zheng $\mathrm{H}$ and Ouyang G: Periostin, a multifunctional matricellular protein in inflammatory and tumor microenvironments. Matrix Biol 37: 150-156, 2014.

18. Koh SJ, Choi Y, Kim BG, Lee KL, Kim DW, Kim JH, Kim JW and Kim JS: Matricellular protein periostin mediates intestinal inflammation through the activation of nuclear factor $\kappa \mathrm{B}$ signaling. PLoS One 11: e0149652, 2016.

19. Taniguchi K, Arima K, Masuoka M, Ohta S, Shiraishi H, Ontsuka K, Suzuki S, Inamitsu M, Yamamoto KI, Simmons O, et al: Periostin controls keratinocyte proliferation and differentiation by interacting with the paracrine IL-1 $\alpha / \mathrm{IL}-6$ loop. J Invest Dermatol 134: 1295-1304, 2014.

20. Neurath MF, Finotto S and Glimcher LH: The role of Th1/Th2 polarization in mucosal immunity. Nat Med 8: 567-573, 2002

21. Liu WZ, He MJ, Long L, Mu DL, Xu MS, Xing X, Zeng X, Liao G, Dan HX and Chen QM: Interferon- $\gamma$ and interleukin- 4 detected in serum and saliva from patients with oral lichen planus. Int J Oral Sci 6: 22-26, 2014.

22. Masuoka M, Shiraishi H, Ohta S, Suzuki S, Arima K, Aoki S, Toda S, Inagaki N, Kurihara Y, Hayashida S, et al: Periostin promotes chronic allergic inflammation in response to Th2 cytokines. J Clin Invest 122: 2590-2600, 2012.

23. Sharma R, Sircar K, Singh S and Rastogi V: Role of mast cells in pathogenesis of oral lichen planus. J Oral Maxillofac Pathol 15: 267-271, 2011.

24. Pujari R and Vidya N: Mast cell density in oral submucous fibrosis: A possible role in pathogenesis. Int J Health Sci (Qassim) 7: 23-29, 2013

25. Huang Y, Liu W, Xiao H, Maitikabili A, Lin Q, Wu T, Huang Z, Liu F, Luo Q and Ouyang G: Matricellular protein periostin contributes to hepatic inflammation and fibrosis. Am J Pathol 185: 786-797, 2015.

26. Kim DW, Kulka M, Jo A, Eun KM, Arizmendi N, Tancowny BP, Hong SN, Lee JP, Jin HR, Lockey RF, et al: Cross-talk between human mast cells and epithelial cells by IgE-mediated periostin production in eosinophilic nasal polyps. J Allergy Clin Immunol 139: 1692-1695.e6, 2017.

27. Ziegler SF, Roan F, Bell BD, Stoklasek TA, Kitajima M and Han H: The biology of thymic stromal lymphopoietin (TSLP). Adv Pharmacol 66: 129-155, 2013.

28. Sun M, Tan W, Liu S, Liu G, Zhang X, Wang N, Qu X and Wei F: In situ expression and serum level of thymic stromal lymphopoietin in oral lichen planus. J Oral Pathol Med 43: 740-745, 2014.

29. Akasaki S, Matsushita K, Kato Y, Fukuoka A, Iwasaki N, Nakahira M, Fujieda S, Yasuda K and Yoshimoto T: Murine allergic rhinitis and nasal Th2 activation are mediated via TSLPand IL-33-signaling pathways. Int Immunol 28: 65-76, 2016.

30. Takahashi N, Sugaya M, Suga H, Oka T, Kawaguchi M, Miyagaki T, Fujita $\mathrm{H}$ and Sato S: Thymic stromal chemokine TSLP acts through Th2 cytokine production to induce cutaneous T-cell lymphoma. Cancer Res 76: 6241-6252, 2016. 